\title{
ICT Based Pest Surveillance and Advisory Services for Rice in Raisen District of Madhya Pradesh, India
}

\author{
Niranjan Singh ${ }^{1}$, Mukesh Sehgal ${ }^{1 *}$, Vikas Kanwar $^{1}$, Prashant $^{2}$ and Kevin Sunil Parker ${ }^{3}$

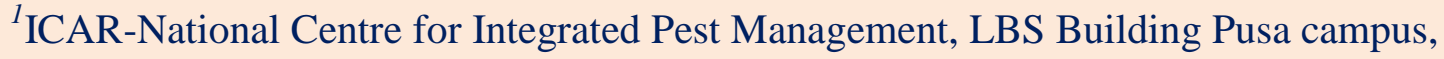 \\ New Delhi-110012, India \\ ${ }^{2}$ M/S Agreeta Solutions Private Limited Pune, M.S, India \\ ${ }^{3} \mathrm{M} / \mathrm{S}$ LT Foods Ltd, Madhya Pradesh, India \\ *Corresponding author
}

\begin{tabular}{|l|}
\hline Ke y w o r d s \\
ICT, IPM, Rice \\
\hline Article Info \\
\hline $\begin{array}{l}\text { Accepted: } \\
\text { 20 February } 2019 \\
\text { Available Online: } \\
\text { 10 March } 2019\end{array}$ \\
\hline
\end{tabular}

A B S T R A C T

Integrated Pest Management (IPM) is knowledge intensive requires holistic approach, expert advice timely decision making and action on fast track. Needs of farmer in pest management revolves around pest diagnostics, surveillance, forecasting and dissemination of expert information in short time. Recent improvement form research brought considerable change in the cropping system and allowed farmer to grow several crops throughout the year, which were very seasonal in the past. IPM practitioners or farmers require timely access to the relevant pest management information/knowledge and expertise so to reduce the pesticide load to have better soil and human health. So the improved methods of Information and Communication Technology (ICT) such as Decision Support Systems (DSSs) greatly help the farmers in accessing the pest management information and expertise. DSSs are software tools that support decision-making activities. They collect, organize, integrate and analyze all types of information required for decision making and finally use the analysis to recommend the most appropriate action. One such ICT based pest surveillance and advisory services for rice in Raisen district of Madhya Pradesh was initiated in active collaboration of M/s Agreeta and M/S Dawat Foods Private ltd wherein ICAR-NCIPM collaborated as consultant.

\section{Introduction}

Information and Communication Technology (ICT) has become a very powerful information providing system for dissemination of pest management information. The ICT has the potential for improving effectiveness and efficiency of pest management programmes. Its ability to allow quick transfer of information and its ready access as well as the knowledge base assist the plant protection workers in advising farmers appropriately so as to save the crop from pest damage and economic losses by judicious use of timely intervention and relevant pest management inputs. The goal of using ICT for pest surveillance is to capture the pest information from farmer's field, transferring it to a centralized database, compilation, reporting and dissemination of 
data to different stakeholders using internet. In fact, pest surveillance provided the fieldspecific information on pest incidence and crop injury leading to appropriate selection and application of pest management procedures by pest management professionals. Fields are scouted to determine what pest management practices need to apply and when? Thus, the success of the recommended pest management procedures depended on the accurate and timely completion of all the pest surveillance activities. So, the use of ICT facilitates in reporting pest situations of different locations at a click of mouse and plays an important role in pest management decision making $(1,2)$.

Pest surveillance or monitoring is the cornerstone of the philosophy of integrated pest management (IPM) as compared to calendar-based treatments. IPM stresses monitoring of pest and determines when the action is necessary to be taken. The basic purpose of surveillance is to determine whether pests are present in the field at a level to initiate pest management interventions.

Through regular and systematic pest surveillance, epidemic situations can be avoided by detecting damage before endemic establishment of a pest in any area. The term 'ICT Based Pest Surveillance or e-Pest Surveillance' encompasses computing devices based storage, transfer, retrieval, sharing, and reporting of pest data for appropriate and timely decision-making for better pest management.

ICAR-NCIPM had developed ICT based pest surveillance \& advisory system which has been successfully implemented for different crops in various states for the country. So to provide timely \& correct advice to the farmers on IPM on Rice from Raisen district of Madhya Pradesh, a consultative project "ICT based Pest Surveillance and Advisory services for Rice in Raisen district of Madhya Pradesh" was initiated during 2017-18 by M/S Dawat Foods Private ltd wherein ICARNCIPM collaborated as consultant with the following objectives:

Customisation and implementation of ICT based pest surveillance and advisory System for Rice crop in Raisen district of Madhya Pradesh.

To provide correct and timely pest management advice to the farmers on the basis of field-pest situation.

E-Pest surveillance system would generate pest reports on insect pests and diseases for various locations such as village(s)/ $\operatorname{district}(\mathrm{s})$ on weekly basis in tabular, graphical and map formats. The information would be used for issuing timely pest management advisories to state agencies and farmers.

The project would help planners, researchers and state extension workers to arrive at one platform to plan IPM strategies against the emerging pests.

\section{In this project the Partner's Responsibilities are}

ICAR-NCIPM responsibility was provide consultancy support for development mobile app for capturing pest data from farmer's field, customisation of web reporting and advisory application and its functional maintenance.

Dawat Foods Ltd was to farmers' field scouting, develop mobile app to regularly capture pest data obtained from farmers' field, web service for data transfer to NCIPM server and to dissemination of pest management advisories to the farmers. 


\section{Results and Discussion}

ICAR-NCIPM devised a three tier architecture based system comprising functional components viz. mobile app for pest data capture, web service for data transfer and web based pest reporting \& advisory application.
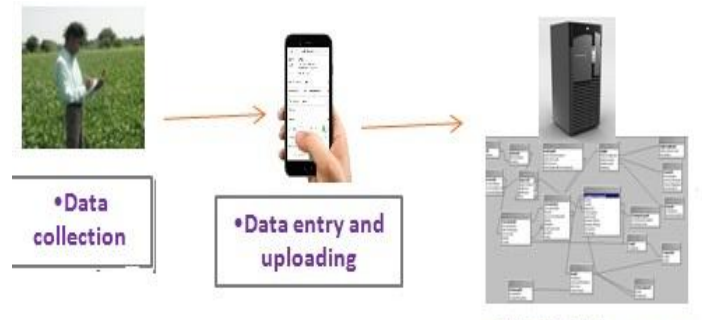

-NCIPM database server

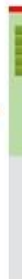

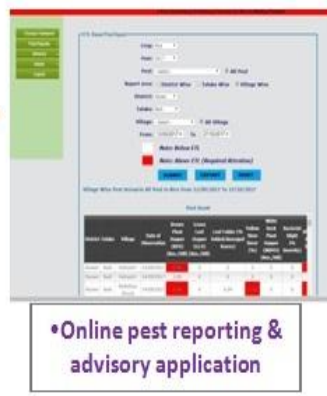

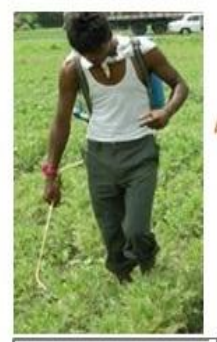

-Advisory dissemination through SMS
M/S Agreeta Solutions Pvt Ltd, an IT firm was assigned development of a user-friendly mobile app for capturing pest data obtained from farmers' field by pest scouts and web service for remote data transfer by DAWAT FOODS ltd. ICAR- NCIPM elaborated the developer about all the processes involved in ICT based pest surveillance and advisory system and due consultancy service were provided for development of mobile app. Relevant customised database structure was also provide to the developer and thus an appropriate app was designed and developed. The master data was hosted into the database. A web service was also designed for remote data transfer from formers fields to the server installed in NCIPM, New Delhi. NCIPM also customised its web based pest reporting application as per this activity. Pets reporting application had three modules admin, pest data reporting, activity tracking and advisory dissemination (Fig. 1-3 and Table 1).

Table.1 Area of operation and pest data entries

\begin{tabular}{|c|c|c|c|c|}
\hline \multirow{2}{*}{ District } & Taluka & Village & $\begin{array}{r}\text { Pest data entries } \\
\text { (nos) }\end{array}$ & Area (ha.) \\
\hline \multirow{2}{*}{ Raisen } & Badi & 24 & 104 & \multirow{2}{*}{20,000} \\
\cline { 2 - 4 } & Baraily & 32 & 99 & \\
\cline { 2 - 4 } & Goharganj & 1 & 2 & \\
\hline \multirow{2}{*}{ Total } & $\mathbf{3}$ & $\mathbf{5 7}$ & $\mathbf{2 0 5}$ & \\
\hline
\end{tabular}


Fig.1 Pest/diseases status during 2017 as produced by the system

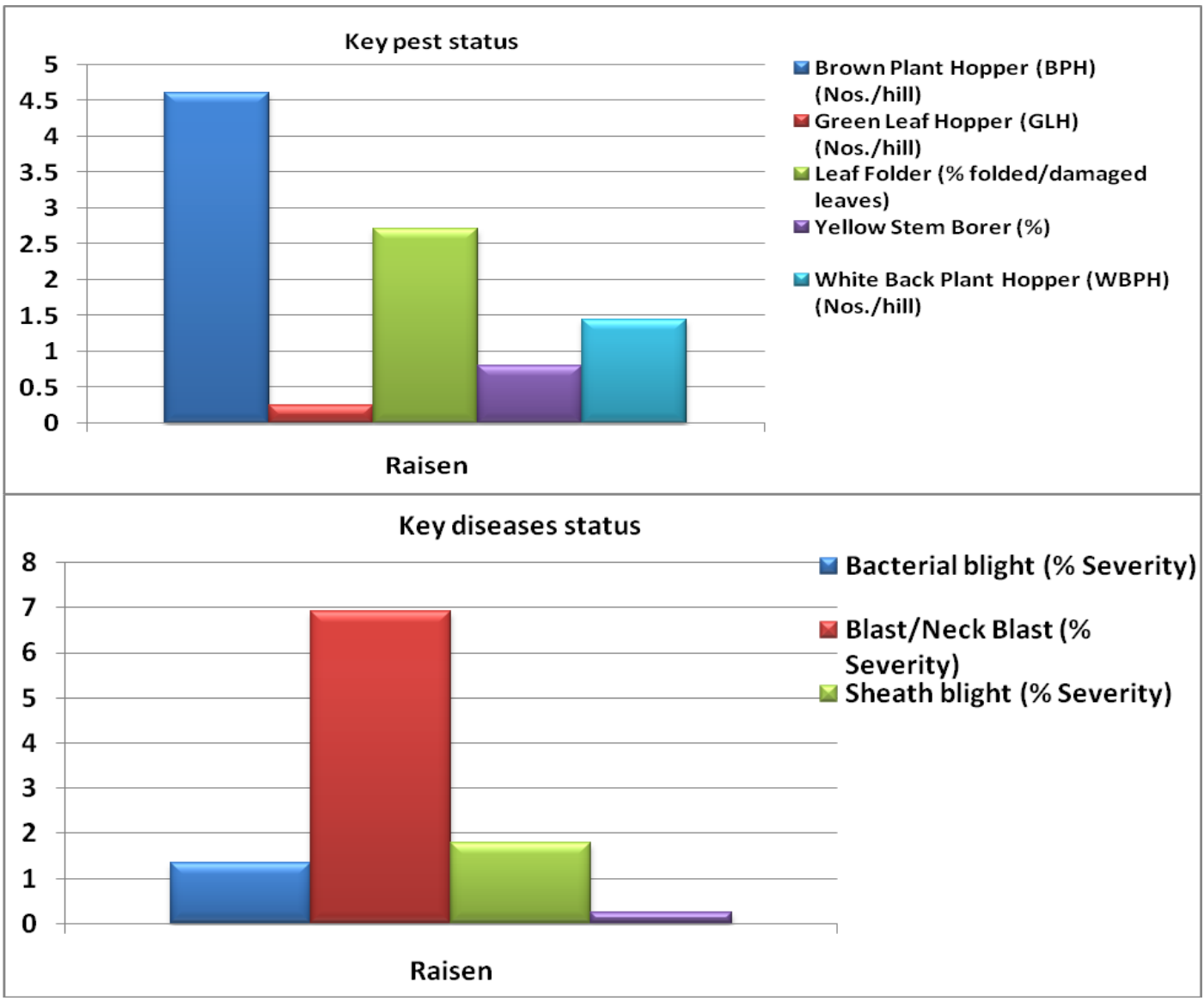

Web address of the reporting and advisory application: http://www.ncipm.org.in/e-pest_mp

Fig.2 Start page

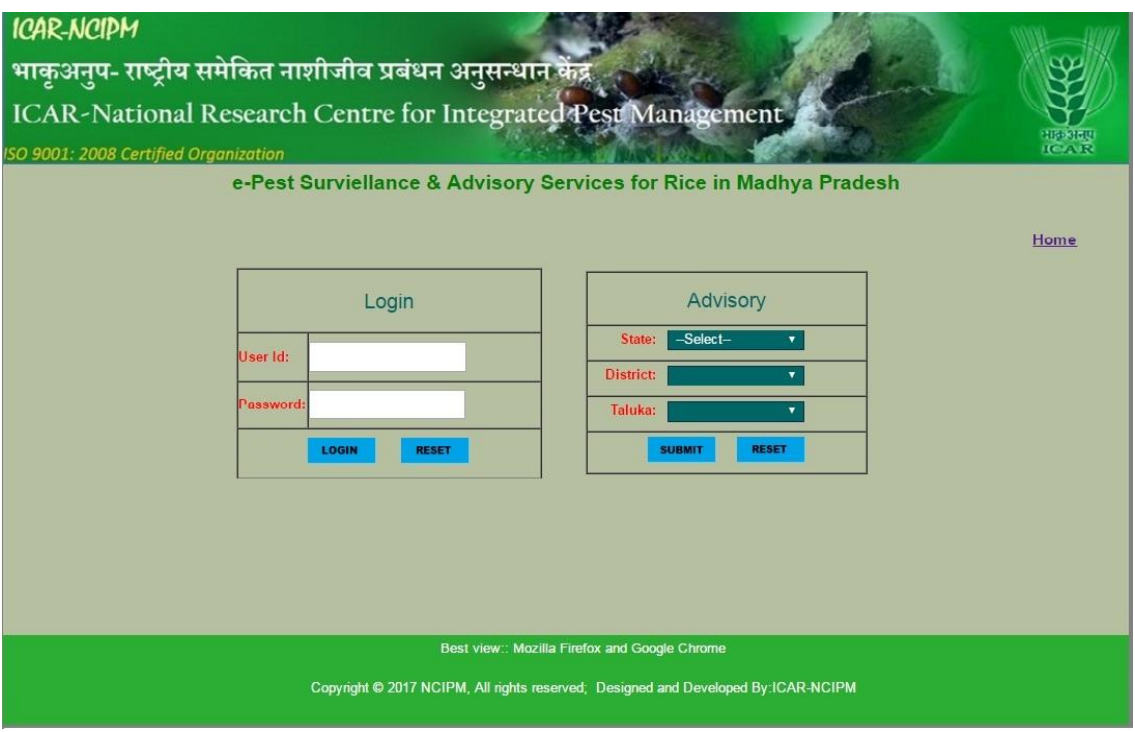


Fig.3 ETL based reporting

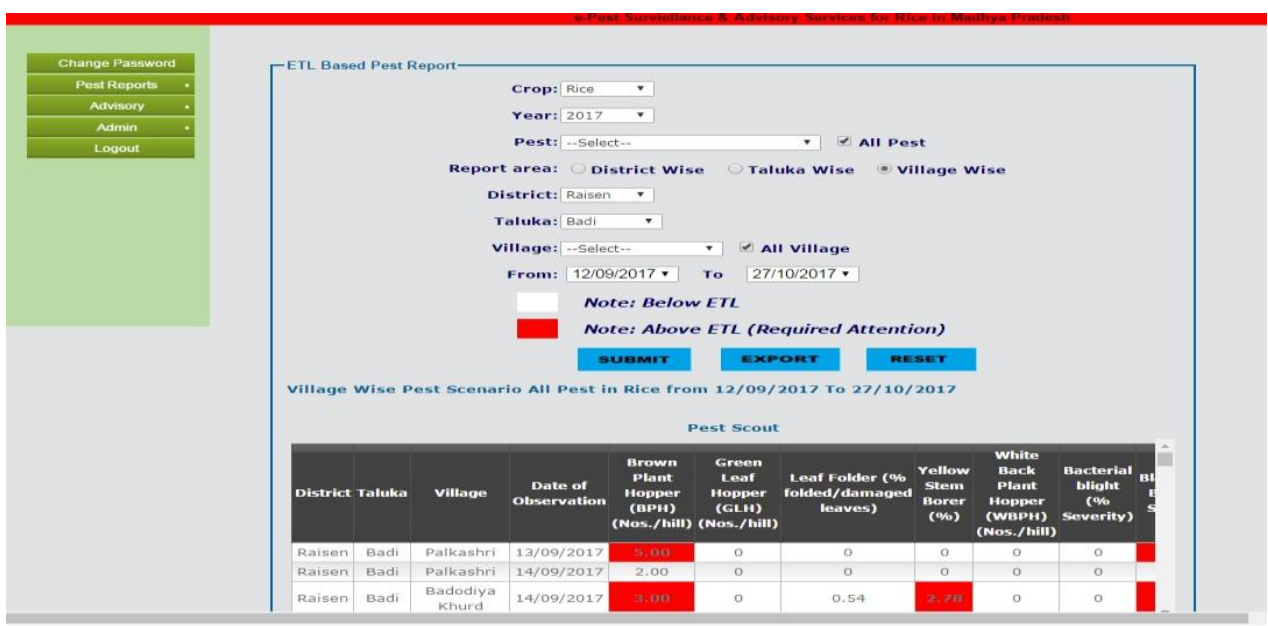

Reporting app is software is functional at NCIPM web page (add mentioned above) and data can be accessed using user Id and login password provided to selected users

The application had proviso to produce two kind of pest reports viz. General pest reports and ETL based pest reports produced in two formats i.e. tabular and graphical (3, 4). System had there kind of users admin, approval officers and pest experts. Admin users are responsible for user creation and master data maintenance. Approval officers are to approve the data transferred by pest scouts to the database and expert were to generate pest reports and disseminate pest management advisories to the registered farmers if pest repots warranted so any location. Web component of the system was hosted on NCIPM server and its functional maintenance was carried successfully.

\section{References}

1. Fishel Fred, Bailey Wayne, Boyd Micheal, Johnson Bill, O’Day Maureen,
Sweets Laura and Wiebold (2009). Introduction to Crop Scouting in $\mathrm{MU}$ manual IPM1006, pp 3-22.

2. International Standards for Phytosanitary Measures (ISPM) No 17 Pest Reporting 2002. FAO, Rome.

3. Singh, N., Jeyakumar P., Bambawale, O. M.,Vennila S.,Kanojia A. K., Bhagat, Sathya S. K. (2012). E-pest surveillance system for soybean (Glycine max) and cotton (Gossypium spp) crops. Indian Journal of Agricultural Sciences, 82 (9): 800-807.

4. Singh, N., Jeyakumar P. and Vennila S. (2014). Area wide e-pest surveillance for soybean in Maharashtra. Soybean Research (special issue no. 2): 249255.

\section{How to cite this article:}

Niranjan Singh, Mukesh Sehgal, Vikas Kanwar, Prashant and Kevin Sunil Parker. 2019. ICT Based Pest Surveillance and Advisory Services for Rice in Raisen District of Madhya Pradesh, India. Int.J.Curr.Microbiol.App.Sci. 8(04): 2936-2940.

doi: https://doi.org/10.20546/ijcmas.2019.804.340 